\title{
INFLUENCE OF ENVIRONMENTAL LANDSCAPE STRUCTURE ON THE DISTRIBUTION FEATURES OF PLANT COMMUNITIES IN GREEN PARKS
}

\author{
PENG, Y. \\ Hunan International Economics University, Changsha 410006, China \\ (e-mail: 451058850@qq.com; phone: +86-186-8495-1668) \\ (Received $7^{\text {th }}$ Jun 2019; accepted $10^{\text {th }}$ Oct 2019)
}

\begin{abstract}
Green parks are indispensable to urban ecosystem, and critical to living environments, urban greening and city development. Based on the theory of landscape ecology, this paper explores how environmental landscape structure (ELS) affects the distribution features of plant communities in several green parks in Jiangmen, southern China's Guangdong Province. The study was carried out with analytical hierarchy process (AHP), geographic information system (GIS) and remote sensing (RS). The research results show that: Compared to the other two parks, Penglai Park, a downtown park surrounded by residential buildings and highways, boasts a high overall temperature, and witnesses limited variations in temperature and PM10. In addition, this park outperforms the other two parks in plant height, the density/overall height/mean coverage of shrub and herb layers, as well as the ecological benefit. In contrast, Jiangbin Park, which is greatly affected by wind from the nearby river, saw great variations in the temperatures inside and outside plant communities and the PM10. As a result, this park lags behind the other two parks in the following aspects: the average height/average coverage of shrub and herb layers, and the mean diameter at breast height (DBH) of arbor layer. The research findings provide a good reference to optimizing the plant communities in green parks and promoting urban ecology.
\end{abstract}

Keywords: environmental landscape structure (ELS), urban park, plant community, distribution features, temperature changes, PM10, urban green park protection

\section{Introduction}

Green parks are an important part of urban ecosystems and the most concentrated areas of urban biodiversity and green spaces (Kruess, 2003). They provide citizens with recreation and fitness places, and have the ecological functions of conserving water, purifying air, reducing noise, and regulating the local climate of the city (Schmucki et al., 2012). The collection of all plants living in a certain area is called a plant community (Svenning et al., 2004). Plant communities are basic components of green parks, and a reasonable plant community layout is the basis for maintaining a green park and exerting its ecological role (Wallgren et al., 2009). In the plant communities, there are certain correlations between the plants and the environment, and between the plants; the surrounding environment has a strong influence on the growth of plants. Therefore, studying the influence of ELS on the distribution features of park plant communities is of great significance.

At the end of the 18th century, in order to solve the problem of urban development and the quality of urban living environment, foreign countries began to study the construction of urban green parks, and the Regent's Park and the Birkenhead Park in England were built in this context (Miller et al., 2016). Subsequently, ecological design has become a main trend for green parks in western countries. In the 19th century, designers chose different tree species and designed a number of green parks according to the structure of the natural communities (José et al., 2016). In the 1920s, designers and ecologists such as Broerse and Springer imitated the natural plant communities and 
their habitats to create urban ecological gardens (Chiron et al., 2014). China's research on landscape ecology and urban green parks started relatively late, but in recent years, as people are paying more attention to the urban ecological environment, Chinese landscape architects have also applied the ecological concept to the design of urban green parks (Davidson et al., 2011). In 1998, in order to effectively transform an urban garbage dump, designers used native plants to build artificial plant communities and construct the Shimen Park in Dashiba, Chongqing city (Amici et al., 2015). Ding Fenghua et al. took the Changsha Martyrs Park as an example and analyzed its current plant landscaping situations (Wrbka et al., 2008). Liu Yanhong et al. investigated the biodiversity characteristics and plant species of urban green parks in Beijing (Goodwin and Fahrig, 2002). Zhang Jing et al. classified the typical plant communities of green parks in Shanghai (Moebiusclune et al., 2013). Concerning the researches on plant communities and environmental factors, current domestic and foreign studies focus mostly on the landscape functions, maintaining biodiversity, cooling and humidifying, and other aspects (Rodrigo León Cordero et al., 2016). The comprehensive effect of plant community structure, the structure model of plant communities and environmental factors based on $3 \mathrm{~S}$ technology, the dynamic monitoring of plant community structure, and the quantitative analysis of their correlations, will be the main trends and focuses of researches in the future (Bouasria et al., 2012).

Based on the above analysis, this paper aims to study the influence of environmental landscape structure on the distribution features of plant community in green parks by selecting Jiangbin Park, Penglai Park and Donghu Park in Jiangmen city as the research area, and analyzes the plant community structure features of these parks according to the three layers: arbor layer, shrub layer and herb layer; three indices of diversity index, ecological advantage index and richness index have been selected to analyze the structure features of the plant communities in the three parks; meanwhile two ecological factors of temperature and PM10 which are largely affected by the environmental landscape structure have also been selected to analyze the influence of ELS on the ecological factor features of plant communities in the park; then this paper comprehensively compares the plant community distribution features of each park under different ELS conditions and proposes related suggestions for the optimization of plant communities in the parks, in the hopes of providing relevant references for the construction of eco-cities.

\section{Materials and methods}

\section{Research objects and methods of plant community structure in major regions}

\section{Research object}

The distribution of plant communities is largely interfered by the surrounding landscape pattern and human factors, which leads to large differences between plant communities in parks and in natural state. This study used GIS and RS technology to obtain the overall plan of Jiangmen City, Guangdong Province, China. After systematic investigation of the vegetation in the parks of Jiangmen City, this paper selects Jiangbin Park (sample area 135,772 $\mathrm{m}^{2}$ ), Penglai Park (sample area 68,732 $\mathrm{m}^{2}$ ) and Donghu Park (sample area $87,521 \mathrm{~m}^{2}$ ) in Jiangmen city as the research areas. Figure 1 shows the specific location of these three parks in Pengjiang District: 1 for Penglai Park, 2 for Jiangbin Park, 3 for Donghu Park. In addition, it uses AHP to conduct sampling and 
survey on the target areas. The sampling area of Jiangbin Park was $1,800 \mathrm{~m}^{2}$ (east longitude 113.118431, north latitude 22.602591), Penglai Park sampling area was $1,800 \mathrm{~m}^{2}$ (east longitude 113.08728, north latitude 22.581711), and Donghu Park sampling area was $2,100 \mathrm{~m}^{2}$ (east longitude 113.087898, north latitude 22.591829). Excel software and landscape pattern analysis software were used for calculation.

Founded in 1958 and opened to the public in July 2014, Donghu Park is located in the center of Jiangmen with the green ecology as the theme. It covers an area of 53 ha, including 17 ha of lake area. It has the elegant restaurant and tea house, as well as the specialties of the hometown. Jiangbin Park is located on the Xijiang River in the North Street of Jiangmen City, covering an area of 3.8 ha. It was built in 1984 as the only park in the city for barbecue. It also has an open-air lounge. Penglai Park was built in 1983 and covers an area of 0.95 ha. It is located at the intersection of Penglai Road and Jianshe Road in Jiangmen City. It was first built with plant landscaping and was renamed as Children's Park in 1990.

\section{Calculation methods}

(1) Diversity index $\left(D_{1}\right)$

$$
D_{1}=1-\sum_{i=1}^{s} \frac{N_{i}\left(N_{i}-1\right)}{N(N-1)}
$$

The larger the $\mathrm{D}_{1}$ value, the higher the diversity (Ames et al., 2016).

(2) Ecological advantage index $\left(D_{2}\right)$

$$
D_{2}=\sum_{i=1}^{s} \frac{N_{i}\left(N_{i}-1\right)}{N(N-1)}
$$

The smaller the $\mathrm{D}_{2}$ value, the higher the diversity and the smaller the ecological advantage (Brunzel et al., 2004).

(3) Richness index (R)

$$
R=\frac{S-1}{\ln N}
$$

where: $\mathrm{N}$ is the number of individuals of all species, $\mathrm{N}_{\mathrm{i}}$ is the number of individuals of species $\mathrm{i}$, and $\mathrm{S}$ is the number of plant species within the sampling area.

\section{Selection of ecological factors}

The various environmental factors that affect biological organisms are called ecological factors, and there are many types of ecological factors. No matter which type, all ecological factors would influence the survival, reproduction and various functions of plant individuals and the whole plant community, moreover, there are interactions among the ecological factors, which would also have an impact on the plant 
community; on the one hand, ecological factors are related to season, climate and other factors in the nature, on the other hand, they are also affected by the landscape of surrounding environment. In order to study the influence of ELS on the distribution features of plant communities in green parks, this paper selects two ecological factors, temperature and PM10 (Herrera et al., 2016), which are strongly influenced by environmental landscape, as the objects of measurement to measure the ecological factors of plant communities inside and outside the parks.

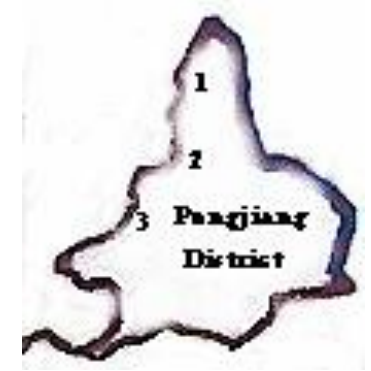

Figure 1. The specific location of the three parks in the Pengjiang District

The temperature and PM10 were measured using the Testto608-H2 dual-purpose thermometer and the hand-held PM10 hand-held dust meter respectively. The measuring instruments were placed at a height of $1.5 \mathrm{~m}$ from the ground. For the external ecological factors of plant community the measuring instruments were mainly placed in the park square and lawn, while for the internal ecological factors of the plant community, the instruments were placed in a sample plot with rich community, with the central position of the shade as the main measurement point. Figure 2 shows the pictures of the measured temperature and PM10 at the experimental site of Donghu Park.

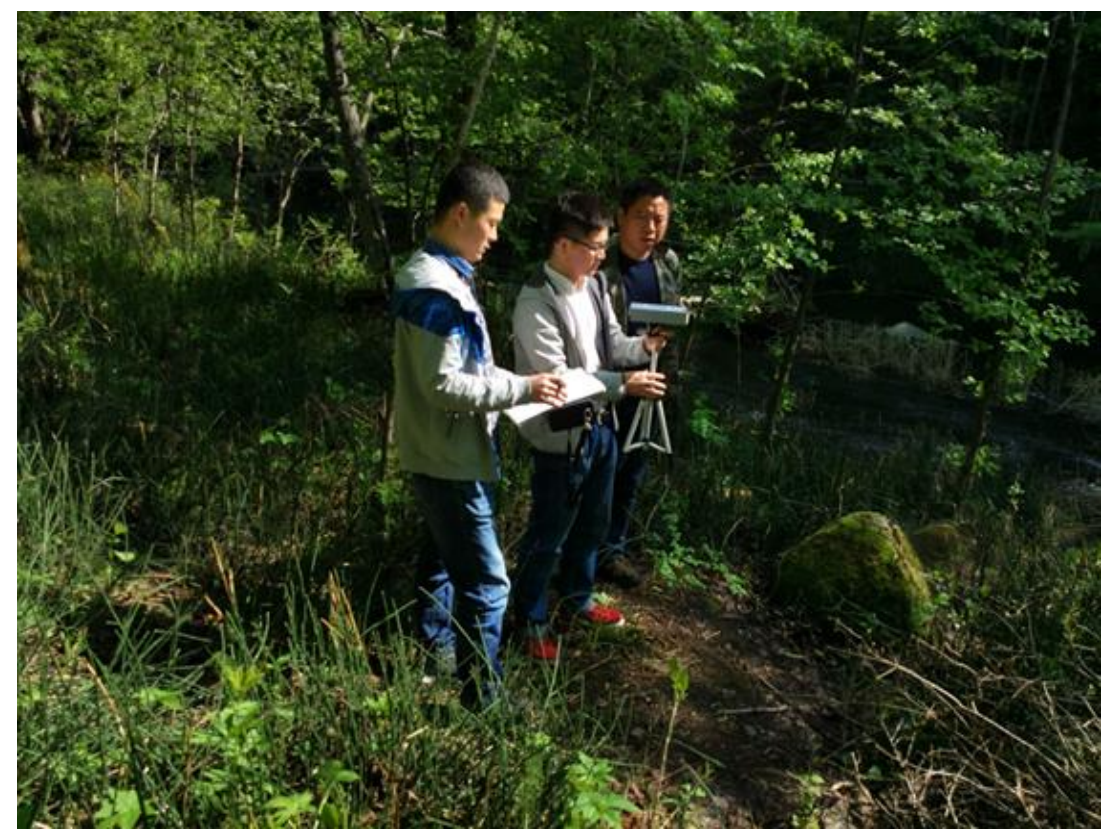

Figure 2. Temperature and PM10 picture of the experimental site of Donghu Park 


\section{Results}

\section{Analysis of plant community structure features}

Through investigation, the plant communities in green parks in Jiangmen city were divided into three community layers: the arbor layer, the shrub layer and the herb layer. Figures 3-5 show the statistical results of the structure features of plant communities in the three parks (number of plants, average height, average coverage). Figure 6 shows the average $\mathrm{DBH}$ of the arbor layer.

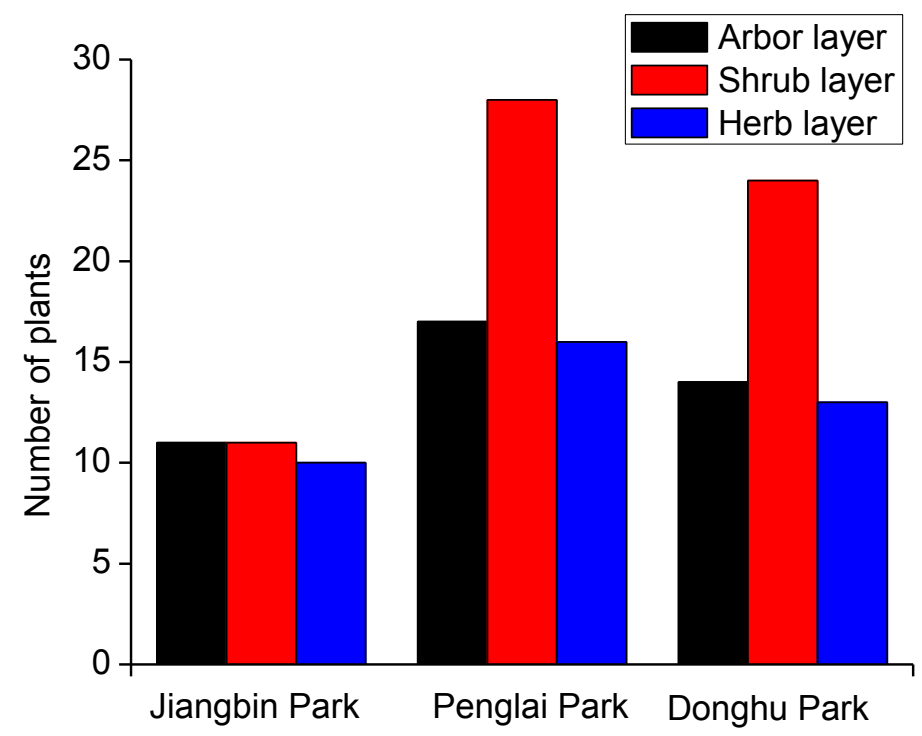

Figure 3. Number of plants of each community layer in the three parks

It can be seen from Figure 3 that the number of shrub layer plants in the three parks is the largest, and the number of herb layer plants is the smallest; in the Jiangbin Park, the number of arbor layer plants, shrub layer plants, and herb layer plants are basically the same, and are much less than those of the Penglai Park and the Donghu Park.

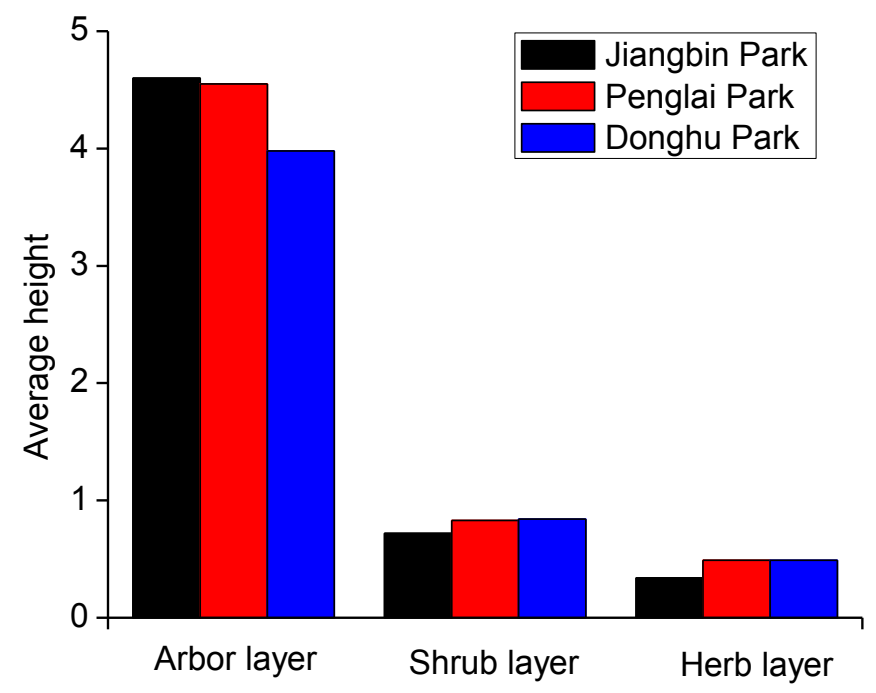

Figure 4. Average height of plant communities in the three parks 
As can be seen from Figure 4, for the Jiangbin Park, the average height of the arbor layer is the highest, and the average heights of shrub layer and the herb layer are the lowest; for the Donghu Park, the average height of the arbor layer is the lowest; There is a small difference in the average height of shrub layer and herb layer between the Penglai Park and Donghu Park, which can be considered to be basically the same.

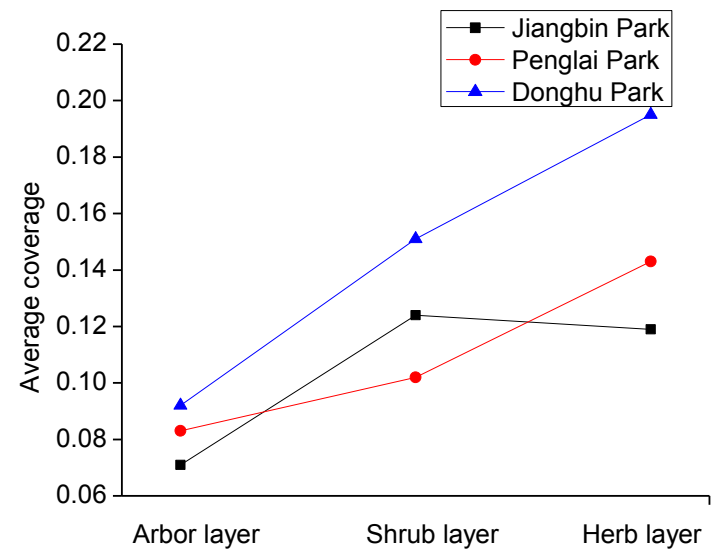

Figure 5. Average coverage of each plant community layer in the three parks

It can be seen from Figure 5 that the average coverages (Average coverage $=$ the sum of the vertical projection areas of all plants of a tree species/the total area of the sample) of the arbor, shrub and herb layers of Donghu Park are much higher than the other two parks. The average coverage of the shrub layer in Jiangbin Park is higher than that of the Penglai Park, while the average coverages of arbor and herb layers of Jiangbin Park are lower than those of the Penglai Park.

Calculate the average $\mathrm{DBH}$ of the arbor layer according to Equation 4:

$$
D B H=\frac{D_{1} \times K_{1}+D_{2} \times K_{2}+D_{3} \times K_{3}+\cdots D_{n} \times K_{n}}{K_{1}+K_{2}+K_{3}+\cdots K_{n}}
$$

where: $\mathrm{DBH}$ is the average $\mathrm{DBH}, D_{1}$ is the first diameter grade value, and $K_{1}$ is number of trees in the first diameter grade.

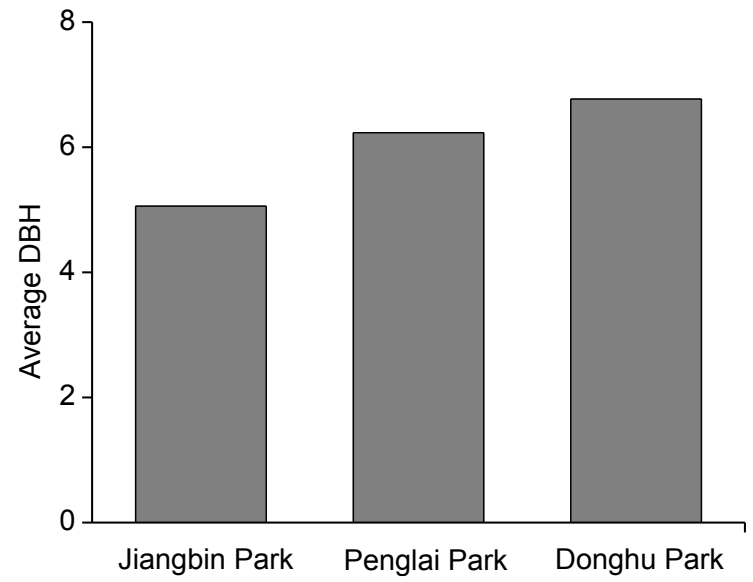

Figure 6. Average DBH of the arbor layer in the three parks 
It can be seen from Figure 6 that the order of the average DBH of arbor layer is: Donghu Park > Penglai Park > Jiangbin Park.

Based on the above analysis, it can be seen that the density and overall height of the shrub layer and the herb layer in Penglai Park are higher and its ecological benefit is better.

\section{Analysis of structure feature indices of plant communities in the parks}

According to Equations 1, 2 and 3, the diversity index ( $\left.\mathrm{D}_{1}\right)$, ecological dominance index $\left(\mathrm{D}_{2}\right)$ and richness index $(\mathrm{R})$ of park plant community structure were calculated. Figure 7 shows structure features of plant communities in the three parks, it can be seen from the figure that in the three parks, the diversity index $\left(D_{1}\right)$ and richness index $(R)$ of the arbor layer, shrub layer and herb layer of the Penglai Park are the highest, while its ecological advantage index $\left(D_{2}\right)$ is the lowest; the ecological advantage index $\left(D_{2}\right)$ of the arbor layer, shrub layer and herb layer of the Jiangbin Park is the highest.

\section{Influence of ecological factors of plant communities in parks}

\section{Temperature changes inside and outside the plant communities in parks}

Table 1 shows the statistics of temperature changes inside and outside the plant communities of each park. It can be seen from the table that the highest temperature of each park appeared in the three months of July, August and September, and the lowest temperature appeared in March and December. Wherein the internal and external temperatures of Jiangbin Park fluctuated greatly, the highest internal and external temperatures were $34{ }^{\circ} \mathrm{C}$ and $35^{\circ} \mathrm{C}$, and the lowest internal and external temperatures were $8{ }^{\circ} \mathrm{C}$ and $6{ }^{\circ} \mathrm{C}$. This is mainly because the Jiangbin Park is located by the riverside near the Jiangbei Bridge, so the temperature is greatly affected by the wind from the river. In the summer, the inside of the plant community is influenced by the evaporation of the river water, so the temperature rises, while in the winter, the influence is smaller, and there are fewer plant types in the plant community, so the warming effect of the plant community is not obvious, plus the influence of the wind from the river, so the temperature is very low in winter. As for the Penglai Park, the internal and external temperature fluctuations were relatively small, its highest temperature and lowest temperatures were $1{ }^{\circ} \mathrm{C}$ lower than that of the Jiangbin Park, respectively, and its external temperature was about $1-2{ }^{\circ} \mathrm{C}$ higher than the internal temperature, this is mainly because the Penglai Park is located in the center of the Jiangmen city, and surrounded by roads and buildings, therefore, its external temperature is higher; inside the park, due to the rich structure of the plant community, and the distribution is reasonable, so the cooling function in the summer and the warming function in the winter are significant.

\section{PM10 inside and outside the plant communities in the parks}

Figure 8 shows the changes of PM10 inside the plant communities of each park, and Figure 9 shows the changes of PM10 outside the plant communities of each park. It can be seen from the figures that the PM10 inside the plant communities of each park was about $10-15 \mu \mathrm{g} / \mathrm{m}^{3}$ lower than the external PM10 level, wherein, the PM10 in the Penglai Park in autumn was as low as $80 \mu \mathrm{g} / \mathrm{m}^{3}$. As for the Jiangbin Park, since it is near the river and the wind is strong in winter, so the PM10 values in summer and winter are much higher than that in the autumn; for the Donghu Park, it is in the leeward 
of production forest farms, so the PM in autumn is higher than that in summer and winter; and for the Penglai Park, its surroundings are mostly residence, plus the distribution of plant community inside the park is reasonable, so the PM10 varies little in summer, autumn and winter.

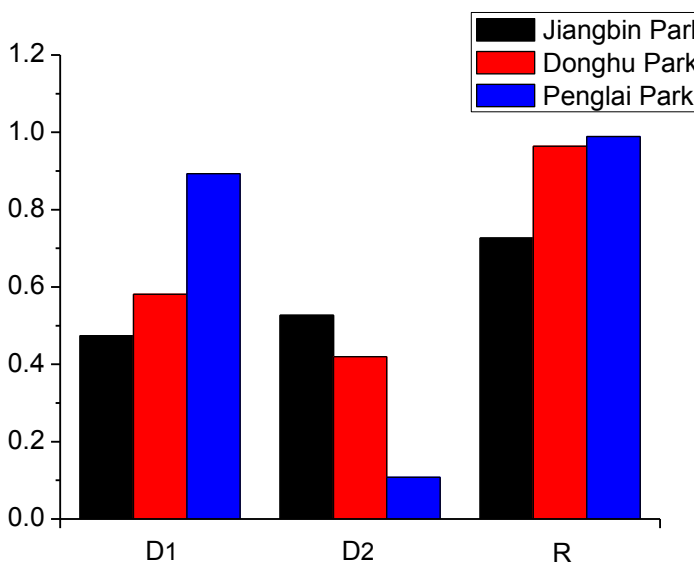

(a) Arbor layer

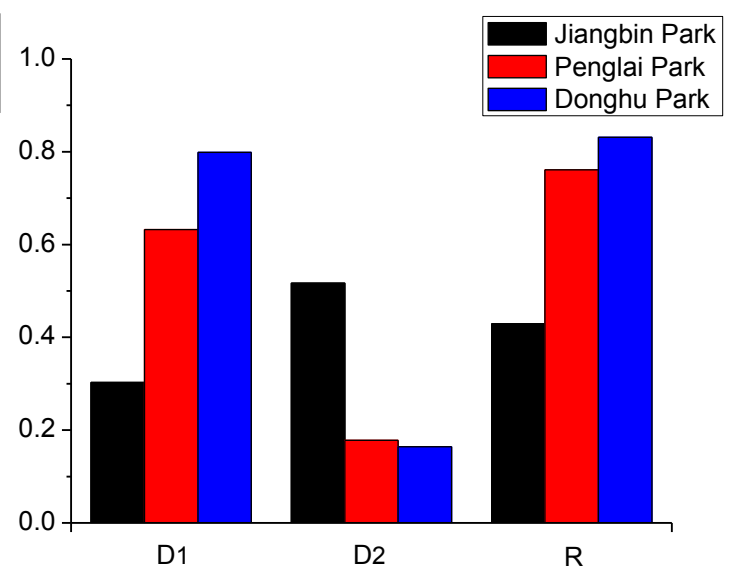

(b) Shrub layer

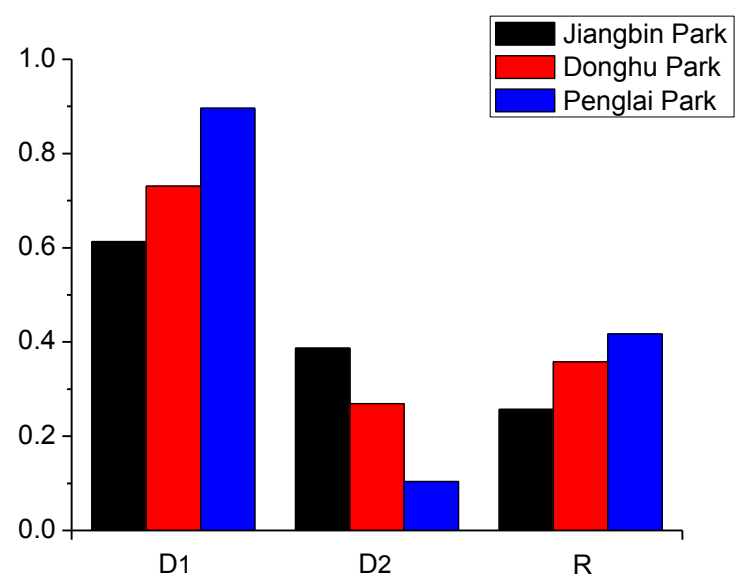

(c) Herb layer

Figure 7. Structure features of plant communities in the three parks

Table 1. Statistics of temperature $\left({ }^{\circ} \mathrm{C}\right)$ changes inside and outside the plant communities of each park

\begin{tabular}{c|c|c|c|c|c|c}
\hline \multirow{2}{*}{ Month } & \multicolumn{2}{|c|}{ Jiangbin Park } & \multicolumn{2}{c|}{ Penglai Park } & \multicolumn{2}{c}{ Donghu Park } \\
\cline { 2 - 7 } & Internal & External & Internal & External & Internal & External \\
\hline 3 & 15 & 15 & 23 & 23 & 18 & 18 \\
4 & 19 & 19 & 26 & 27 & 21 & 19 \\
5 & 22 & 22 & 30 & 29 & 22 & 21 \\
6 & 31 & 33 & 31 & 32 & 24 & 24 \\
7 & 34 & 35 & 32 & 34 & 31 & 32 \\
8 & 32 & 34 & 32 & 33 & 32 & 35 \\
9 & 33 & 34 & 31 & 33 & 32 & 33 \\
10 & 28 & 29 & 27 & 28 & 26 & 27 \\
11 & 14 & 16 & 16 & 14 & 15 & 15 \\
12 & 8 & 6 & 9 & 7 & 8 & 7 \\
\hline
\end{tabular}




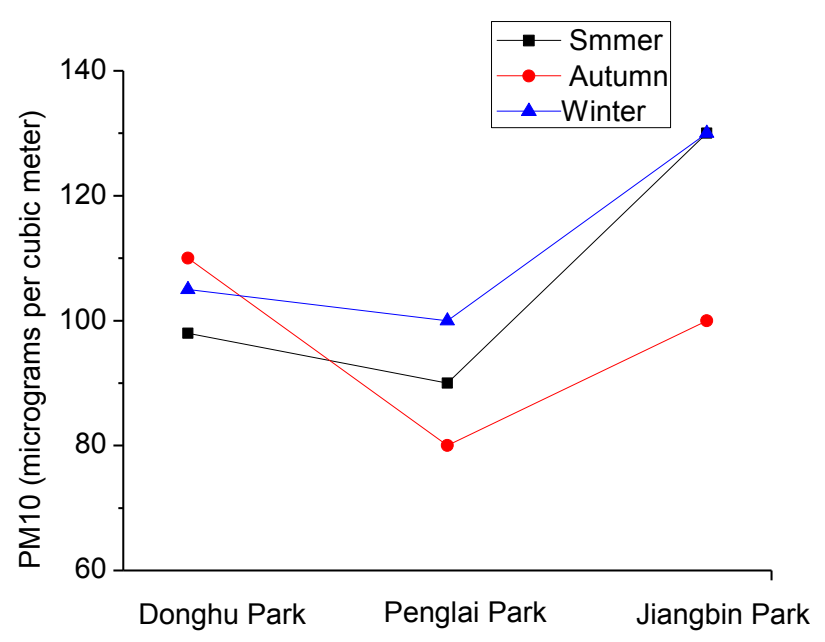

Figure 8. PM10 variation inside the plant communities of each park

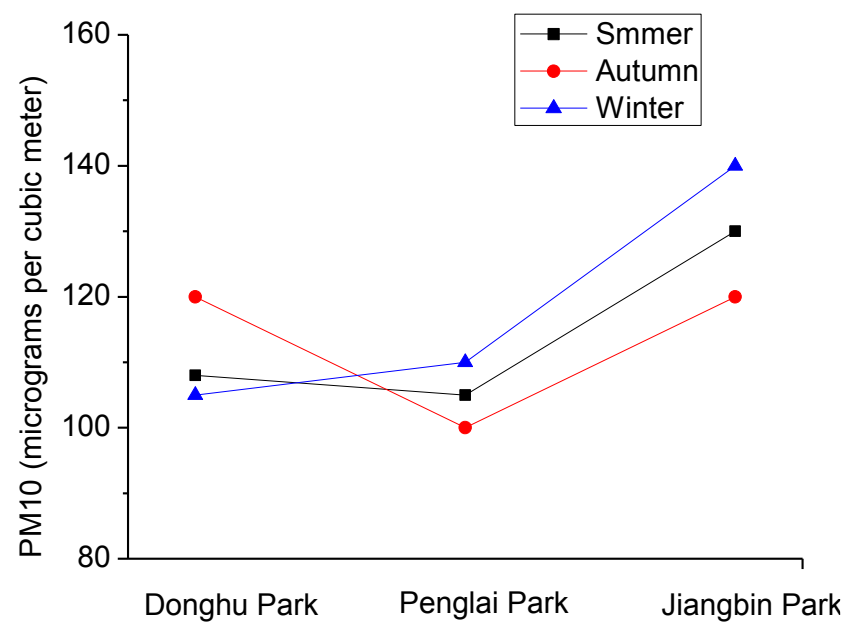

Figure 9. PM10 variation outside the plant communities of each park

\section{Discussion}

\section{Influence of ELS on the distribution features of plant communities in green parks}

According to above analysis results we can see that, the Penglai Park is located in the center of the city, and surrounded by residential buildings and highways, the temperature changes little, and the overall temperature is higher than the other two parks; its fluctuation of PM10 is small, the density, overall height and average coverage of the shrub layer and herb layer, and the ecological benefit of the Penglai Park are all higher than the other two parks, which is basically in line with the previous research results. As for the Jiangbin Park, since it is near the river and greatly affected by the wind from the river, the temperature inside and outside the plant community and the PM10 vary greatly, therefore, its average height and average coverage of the shrub layer and the herb layer, and the average DBH of the arbor layer are all lower than the other two parks. In the past, there have been few studies on the distribution features of plant communities by ecological factors. This study is expected to provide reference for future research in this regard. 


\section{Countermeasures and suggestions for green park protection in Jiangmen City}

\section{Improve urban green space system planning}

Green parks are only a part of the urban green space system, to make the distribution of park plant communities more reasonable, we should reduce damages and development of urban green space and enhance green land construction along highway, in squares and tourist attractions, make use of every single space, form a complete urban green space system, and provide a good ELS for green parks.

Strengthen the design of plant communities in green parks and enrich the diversity of plant communities

When designing the green parks, we should introduce more native tree species and landscapes, enrich the diversity of plant community by planting plants of different heights, and afforest reasonably outside the plant communities, so as to conserve water, lower the temperature and increase relative humidity, thereby improving and exerting the overall ecological benefits of the plant community.

\section{Conclusion}

- The analysis of plant community structure features showed that the order of the average DBH of the arbor layer in the three parks is: Donghu Park > Penglai Park > Jiangbin Park. The density and overall height of the shrub layer and the herb layer in Penglai Park are higher, indicating that the overall ecological benefit of the Penglai Park is better.

- The analysis results of the indices of the plant community structure features showed that, the diversity index $\left(\mathrm{D}_{1}\right)$ and richness index $(\mathrm{R})$ of the arbor layer, shrub layer and herb layer in the Penglai Park are the highest, and its ecological advantage index $\left(D_{2}\right)$ is the lowest.

- The analysis results of the influence of ELS on the distribution features of plant communities in green parks showed that, the Penglai Park is located in the center of the city, and surrounded by residential buildings and highways, both the temperature and the PM10 change little, and its overall temperature is higher than the other two parks; the density, overall height and average coverage of the shrub layer and herb layer, and the ecological benefit of the Penglai Park are all higher than the other two parks. As for the Jiangbin Park, since it is near the river and greatly affected by the wind from the river, the temperature inside and outside the plant community and the PM10 vary greatly, therefore, its average height and average coverage of the shrub layer and the herb layer, and the average $\mathrm{DBH}$ of the arbor layer are all lower than the other two parks.

- Taking the urban green parks of Jiangmen City as examples, this paper studies the influence of environmental landscape structure on the distribution features of plant communities in green parks. It comprehensively compares the distribution features of plant communities in different parks under different environmental landscape structures, and proposes relevant suggestions for the optimization of park plant communities. This shall provide a theoretical reference for urban ecological construction. 


\section{REFERENCES}

[1] Ames, G. M., Anderson, S. M., Wright, J. P., Baltzer, J. (2016): Multiple environmental drivers structure plant traits at the community level in a pyrogenic ecosystem. Functional Ecology 30(5): 789-798.

[2] Amici, V., Rocchini, D., Filibeck, G., Bacaro, G., Santi, E., Geri, F., Landi, S., Scoppola, A., Chiarucci, A. (2015): Landscape structure effects on forest plant diversity at local scale: exploring the role of spatial extent. - Ecological Complexity 21: 44-52.

[3] Bouasria, A., Mustafa, T., Bello, F. D., Zinger, L., Choler, P. (2012): Changes in rootassociated microbial communities are determined by species-specific plant growth responses to stress and disturbance. - European Journal of Soil Biology 52(9): 59-66.

[4] Brunzel, S., Elligsen, H., Frankl, R. (2004): Distribution of the cinnabar moth Tyria jacobaeae L. at landscape scale: use of linear landscape structures in egg laying on larval hostplant exposures. - Landscape Ecology 19(1): 21-27.

[5] Chiron, F., Chargé, Rémi, Julliard, R., Jiguet, F., Muratet, A. (2014): Pesticide doses, landscape structure and their relative effects on farmland birds. - Agriculture, Ecosystems \& Environment 185: 153-160.

[6] Cordero, R. L., Torchelsen, F. P., Overbeck, G. E., Anand, M. (2016): Invasive gorse (Ulex europaeus, Fabaceae) changes plant community structure in subtropical forestgrassland mosaics of southern Brazil. - Biological Invasions 18(6): 1629-1643.

[7] Davidson, J. M., Patterson, H. A., Wickland, A. C., Fichtner, E. J., Rizzo, D. M. (2011): Forest type influences transmission of, Phytophthora ramorum, in California oak woodlands. - Phytopathology 101(4): 492-501.

[8] Goodwin, B. J., Fahrig, L. (2002): Effect of landscape structure on the movement behaviour of a specialized goldenrod beetle, Trirhabda borealis. - Canadian Journal of Zoology 80(1): 24-35.

[9] Herrera, J. M., Isa de Sá Teixeira, Rodríguez-Pérez, J., Mira, A. (2016): Landscape structure shapes carnivore-mediated seed dispersal kernels. - Landscape Ecology 31(4): 731-743.

[10] Kruess, A. (2003): Effects of landscape structure and habitat type on a plant-herbivoreparasitoid community. - Ecography 26(3): 283-290.

[11] Miller, J. E. D., Damschen, E. I., Harrison, S. P., Grace, J. B. (2016): Landscape structure affects specialists but not generalists in naturally fragmented grasslands. - Ecology 96(12): 3323-3331.

[12] Moebiusclune, D. J., Moebiusclune, B. N., Harold, M. van Es, Pawlowska, T. E. (2013): Arbuscular mycorrhizal fungi associated with a single agronomic plant host across the landscape: community differentiation along a soil textural gradient. - Soil Biology \& Biochemistry 64(64): 181-190.

[13] Schmucki, R., Reimark, J., Lindborg, R., Cousins, S. A. O. (2012): Landscape context and management regime structure plant diversity in grassland communities. - Journal of Ecology 100(5): 1164-1173.

[14] Svenning, J. C., Kinner, D. A., Stallard, R. F., Wright, B. M. J. E. J. (2004): Ecological determinism in plant community structure across a tropical forest landscape. - Ecology 85(9): 2526-2538.

[15] Wallgren, M., Bergstrom, R., Danell, K., Skarpe, C. (2009): Wildlife community patterns in relation to landscape structure and environmental gradients in a Swedish boreal ecosystem. - Wildlife Biology 15(3): 310-318.

[16] Wrbka, T., Schindler, S., Pollheimer, M., Schmitzberger, I., Peterseil, J. (2008): Impact of the Austrian agri-environmental scheme on diversity of landscapes, plants and birds. Community Ecology 9(2): 217-227. 